\title{
Knowledge Sharing in Social Media as Moderating Variable between Social Capital Online and Response to Humanitarian Crises
}

\author{
Ahmed Salmen* and Mokhtaruddin bin Ahmed
}

Department of Mass Communication, Center for Language Studies and Human Development, Universiti Malaysia Kelantan, Kelantan, Malaysia

\begin{abstract}
One of the most interesting phenomena to come out of the internet revolution is its utilization as a channel for social development and a contribution to community cohesion. Many volunteers, working in task forces and were recruited through the net, work to improve the lives of many in need people throughout Yemen. This study focused on the knowledge management in social media and turning them into tangible results to develop the behavior of responding to humanitarian crises and creating social cohesion in real society. Based on a quantitative methodology, the data were collected by distributing 530 questionnaires on managers of nonprofit organizations in Yemen which were participating in disaster relief. The data were collected from the questionnaires and analyzed through the quantitative methodology. The results showed that there was a promoted social coordination, volunteering and social cohesion that have resulted in speeding the accessibility of backgrounds for decision making through knowledge management inside social media. These results indicated the importance of developing knowledge management in social media in the process of public communication during disasters in order to alleviate the problem of the delayed response, prevent random relief works and increase community cohesion after the crises that often cause the collapse of social relations as a result of the scarcity of resources.
\end{abstract}

Keywords: Social media; Knowledge management; Volunteerism; Social coordination; Social cohesion; Humanitarian crises

\section{Introduction}

Social media can be described as a "group of internet-based applications that build on the ideological and technological foundations of Web 2.0 and allow the creation and exchange of user-generated content" [1]. Thus, the functionalities they offer are demonstrably suitable to support communication and coordination between the people affected by and volunteers helping during emergencies. They enable real and virtual help activities to be addressed [2]. Social media have been extensively used during various disasters [3]. However, volunteers and the people affected by disasters participated too. In situations where the scale and extent of the difficulties are emergent and therefore not completely known; or where resources may be scarce or inappropriately allocated; and where information unfolds rapidly, the role of unofficial actors can be critical [4].

During a crisis, humanitarian organizations are often riddled with innumerable communication as people attempt to contact with their families and friends in the disaster area, and get access to information on food, shelter and transportation [5]. This was supported by Leong et al. (2015) who confirmed that crisis response phase is a complex set and quick, unexpectedly occurring events. In order to overcome these circumstances, three types of social support are critical: information, material, and emotional support, whereby communities depend on the latest crisis information for guidance in an unfamiliar situation. Society, organization or humanitarian crisis is characterized by non-trivial threats to life, well-being, or other significantly held values, such as, in the case of unpredictability and urgency [6]. Currently, the conflict in Yemen brought about an increase in emergency humanitarian assistance, where humanitarian relief organizations in Yemen are estimated to assist 21.2 million people ( $82 \%$ of the population), who need humanitarian aid to meet their basic needs (UN, 2015).

Social capital and active citizenship are increasingly linked in local organization's relief policies with community cohesion because more people feel as a part of their community and build social capital and more communities will become safer places in many countries around the world [7]. However, sometimes community cohesion during disaster response may encourage members to remain in vulnerable locations because they have a false sense of security or desire to maintain community solidarity. Certain shared practices, beliefs, etc. May lead communities and their members to act in ways that make them more vulnerable [8]. Therefore, one of the most interesting phenomena out of the internet revolution is used as a conduit for social development where volunteers work in teams improve the lives of millions of people all over the world [9].

\section{Social capital online}

Clearly, social media sites are designed to connect people with friends, family, and other strong ties, as well as to efficiently keep in touch with a larger set of acquaintances and new ties. Therefore, they have strong potential to influence others, which often flows from social capital [10]. Usually, receiving messages through social media, from friends is associated with increases in bridging social capital. However, passively using social media, news consumes more time, but nevertheless increases social connectedness and the value of those connections [11].

In recent social capital studies in relation to the network society, the majority of the results claims that the internet encourages social connections and involvement rather than prior concerns of decrease of social involvement or social displacement [12]. According to Kaigo

*Corresponding author: Ahmed Salmen, Department of Mass Communication Center for Language Studies and Human Development, Universiti Malaysia Kelantan, Kelantan, Malaysia, Tel: 711455703; E-mail: Salmeen15@gmail.com

Received February 26, 2018; Accepted March 23, 2018; Published March 29 2018

Citation: Salmen A, Ahmed M (2018) Knowledge Sharing in Social Media as Moderating Variable between Social Capital Online and Response to Humanitarian Crises. J Mass Communicat Journalism 8: 365. doi: 10.4172/2165-7912.1000365

Copyright: (๑ 2018 Salmen A. This is an open-access article distributed under the terms of the Creative Commons Attribution License, which permits unrestricted use, distribution, and reproduction in any medium, provided the original author and source are credited. 
[13], social media can provide social support and social interaction that made possible a wide region during disasters. Social media has become the supplier of information and knowledge for the citizens during disasters in the early days of disasters through building social capital in the virtual community.

Consequently, social media knowledge, such as in Facebook can help individuals, communities, and organizations to share emergency plans and establish emergency networks. Integrating networks into a community's preparedness activities for public emergencies could help to build social capital and community resilience, and make it easier for both professional responders and ordinary citizens to use familiar social media networks and tools during a crisis confirmed that social workers' active involvement in disaster management is pivotal in creating plans that help on providing all required resources before, during, and after a disaster. Social work professionals utilize social capital concepts such as solidarity, social cohesion, volunteer, social coordination, social interaction, and social networks to enhance the capacity of individuals, groups, communities, and organizations to ensure social development. Therefore, social capital is measured through three-dimensional concepts, namely coordination, volunteer and social cohesion in this study $[14,15]$.

Volunteering and informality helped in creating social capital, which has been linked to social cohesion: as a building block of social cohesion [16]. Today, online volunteering means volunteer activities that are completed, in whole or in part, via the internet from a home, work, or public access by computer, usually is in direct support of or through non-profit organization depends on the volunteers [17]. Exposure and attention to social media content during disasters may motivate individuals to become more involved in helping those affected [18]. Social cohesion is a crucial, but an invisible force makes individuals together as a unit in the community. The cohesion itself can be regarded as a dynamic process reflected in the tendency for a group to stick together and remain united in pursuit of its goals and objectives. Although group cohesion is a meaningful topic, contemporary research has paid little attention to the impact of disasters on group cohesion in real-life situations [19].

\section{Knowledge management online}

Knowledge management is not a new concept for agencies involved in disaster response. Since each disaster is unique and presents entirely new environmental, geographical, political, economic, and sociological concerns, it is normal for responders to build new knowledge structures on the fly to capture important information for later reuse. Previous research has shown that in times of disasters, people and organizations improvise and adapt to cope with their new condition and environment [20]. Thus, knowledge systems typically are organized. Such as this knowledge may be quickly adapted and reused for the new response effort. Finally, responders are used to consolidate information quickly and present it to decision makers with the authority to re-task necessary assets [21].

During a disaster, knowledge sharing plays an important role in helping save lives, delivering immediate relief, supporting victims and minimizing the effect of the disaster [22]. According to the United Nations Disaster Assessment and Coordination Team, effective knowledge sharing are important to help coordinate collective efforts among agencies in order to minimize the disaster's effects [23]. Through effective information management, the relevant organizations can access the right information about the disaster, make the right decisions, and plan the appropriate actions. This leads to me, limiting the effects of the disaster, reducing the loss, and quickly redeveloping the victims' wellbeing [24]. During disaster management, information sharing should not be limited among the organizations only, but it should also involve the individuals who are affected by the disaster. Through effective information sharing, they can receive information about the current situation and most important information about food, clothing, and medical supplies [25].

Chiu et al. [26], recognize that a virtual community helped on fostering of the supply of knowledge, namely the willingness to sharing knowledge with other members to build social capital. Thus, they create and maintain the knowledge base through use of social media, helping on providing consistent support to real-time decision-makers in the relief operations during crises, and recommending possible solutions based on the experience and knowledge. Therefore, the knowledge base evolves incrementally over the time that the framework allows for relief organizations to transcend the existing limitations and redundancies created by today's information integration and sharing [27]. Often, disaster information is used to obtain situation awareness about a disaster event, needs assessment, and statistical analysis, while sharing knowledge, and past experience facilitate relief decision making. All of this information and knowledge are collected from various sources and kept either directly or indirectly in the knowledge base [28]. Thus, the use of social media creates the opportunity for organizations to knowledge sharing through knowledge management in internet.

\section{Response to humanitarian crises}

Humanitarian crises are defined by the United Nations as a serious disruption of the functioning of a society, and they refer to disasters which cause widespread human or environmental losses exceed the ability of the affected part of society to cope adequately using only its own resources, where the public participants and emergency managers in the crises need to use information and communication systems in order to decide upon actions [29]. A humanitarian crisis is also defined as a singular event or a series of events that are threatening in terms of health, safety or wellbeing of a community or large group of people (UNICEF, 2015). It may be an internal or external conflict and usually occurs throughout a large land area. Local, national and international responses are necessary in such events [30].

Humanitarian crises can either be natural disasters, man-made disasters or complex emergencies. In such cases, complex emergencies occur because of several factors or events that prevent a large group of people from accessing their fundamental needs, such as food, clean water or safe shelter. Examples of humanitarian crises include armed conflicts, epidemics, famine, natural disasters and other major emergencies. If such a crisis causes large movements of people, it could also become a refugee crisis (UN, 2013). Therefore, humanitarian crises can affect the structures of society by disrupting economic development, increasing income and wealth inequality, marginalizing certain groups due to weak social capital and cohesion among members of society, and leading to large-scale migrations. Crucially, humanitarian crises can also affect in weakening state capacity and legitimacy and creating opportunities for the disgruntled both with violent civil conflict or natural disasters [31]

It is crucial for decision-makers during disaster to keep up with developments towards better elaboration and the provision of appropriate means of facing natural risks. This has been realized through knowledge management in social media by many organizations, governments and companies all over the world [32]. Although social media can positively impact disaster relief efforts, it does not provide 
an inherent coordination capability for easily coordinating and sharing information, resources, and plans among disparate relief organizations and only through social capital online creating. However, applications based on social media applications offer a powerful capability for collecting information from disaster scenes and visualizing data for relief decision making [33].

\section{Research Framework and Theoretical}

The research framework of this study consists of three variables (independent variable, mediating variable and dependent variable). This study is expected to investigate the knowledge management online and mediate the relationship between social capital online and response to humanitarian crisis. According to Lettieri and Savoldelli [34], knowledge management in social media as mediating variable contributes to conceptualize the relationship between independent variable and dependent variable based on clarification about the role of mediating variable.

The Uses and Gratifications (U\&T) theory are adopted by this study as the underpinning theory. The former serves as the main theory. More specifically, in literature, Baran and Davis [35] confirmed that this theory discusses how users deliberately choose media that will satisfy given needs and allow them to enhance knowledge, relaxation, social capital, social interactions/companionship, diversion, or escape [36]. To understand social media use among the satisfactions derived from using the social media to gain knowledge about humanitarian crises, the uses and gratifications (U\&G) theory was used as the theoretical framework of this study as recommended by Blumler and Katz [37] (Figure 1).

\section{Methodology and Analysis}

\section{Sample selection}

Data was collected via a self-administrated questionnaire survey

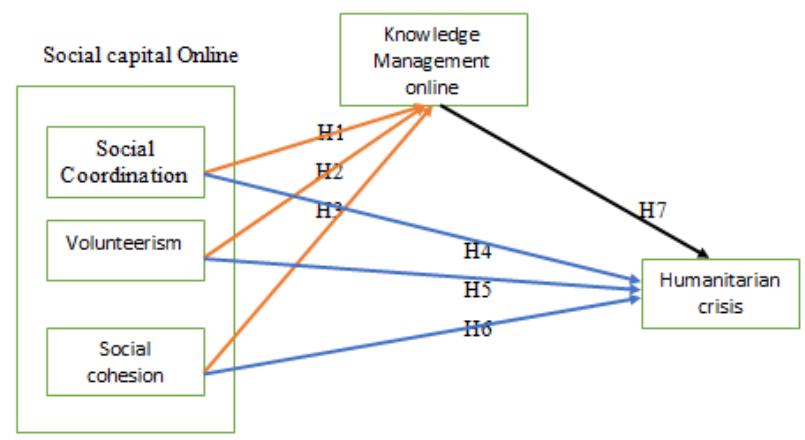

$\mathrm{H} 1$ : Social Coordination has a significant and positive influence on Knowledge management online.

$\mathrm{H} 2$ : Volunteerism has a significant and positive influence on Knowledge management online.

H3: Social cohesion has a significant and positive influence on Knowledge management online.

$\mathrm{H} 4$ : Social Coordination has a significant and positive influence on response to Humanitarian crisis.

H5: Volunteerism has a significant and positive influence on response to Humanitarian crisis

H6: Social cohesion has a significant and positive influence on response to Humanitarian crisis.

$\mathrm{H} 7$ : Knowledge management online mediates the relationship between Social Coordination and response to Humanitarian crisis

Figure 1: Conceptual framework and hypotheses model. using random sampling. Accordingly, the study found that the stratified random sampling was used and randomly drawn as from non-profit organizations in Yemen. The study found that the stratified random sampling method is widely used in the previous studies [38,39].

The total number of distributed surveys and questionnaires were 530, 397 surveys and questionnaires were returned which represented approximately $75 \%$ response rate. Due to some cases of missing values, 25 questionnaires were excluded from the analysis and 18 cases were outlier; thus, a total of 354 usable questionnaires was utilized with a $73 \%$ response rate. The sample size of $\mathrm{N}=354$ was considered as sufficient for this study. The study sample size $(\mathrm{N}=354)$ achieved the ratio of $5: 1[40]$.

\section{Descriptive statistics for constructs}

Mean and standard deviation (SD) of the measurement scales were calculated. This study used a seven-point Likert scale ranging from "1" strongly disagree to "7" strongly agree. The main goal of the study is to explore the gauge of organization performance among manufacturing companies in Jordan Table 1 shows that the highest mean was Social Coordination with 4.134 out of a maximum 5 making up $82 \%$. On the other hand, Social cohesion had the lowest mean with 3.244 making up $65 \%$ and the mean of these values (overall mean) was 3.639 out of a maximum 5 (more than 3 ). Table 1 presents the descriptive statistics for all variables. In addition, the standard deviations (S.D) for all variables range from 0.822 to 1.164 , which reflects the existence of considerable acceptable variability within the data set.

\section{Reliability and composite reliability}

This study shows two conducted types of reliability were conducted. The first type is Cronbach's alpha via the use of SPSS 22.0 and the second type is composite reliability (CR). The current study indicates the reliability (Cronbach's alpha) value ranged from 0.855 to 0.932 while composite reliability (CR) values ranged values ranged from 0.865 to 0.932 . Therefore, all values of reliability and composite reliability constructs were greater than the recommended value of above 0.60 . Table 2 below presents reliability (Cronbach's alpha) and composite reliability for the constructs.

\section{Confirmatory factor analysis (CFA)}

The first purpose of conducting CFA was to exclude any scale item or latent factor that was not well fit and thus create the best possible

\begin{tabular}{|c|c|c|c|c|c|c|}
\hline Variable & Demission & Code & \multicolumn{2}{|c|}{ Mean } & \multicolumn{2}{|c|}{ S.D. } \\
\hline & Knowledge Sharing & KNW & 3.475 & & 1.143 & \\
\hline \multirow{2}{*}{$\begin{array}{c}\text { Social Capital } \\
\text { Online }\end{array}$} & Social Coordination & SCO & 4.134 & & 0.893 & \\
\cline { 2 - 4 } & Volunteerism & VOL & 3.631 & \multirow{2}{*}{3.669} & 1.164 & \multirow{2}{*}{1.102} \\
\cline { 2 - 4 } & Social cohesion & SOH & 3.244 & & 1.086 & \\
\hline \multirow{2}{*}{ Overall } & Humanitarian Crisis & HUM & 3.711 & & 0.822 & \\
\hline
\end{tabular}

Table 1: Descriptive statistics for variables.

\begin{tabular}{|l|c|c|c|c|}
\hline Variables & Code & $\begin{array}{c}\text { Number of } \\
\text { items }\end{array}$ & $\begin{array}{c}\text { Cronbach's } \\
\text { alpha }\end{array}$ & $\begin{array}{c}\text { Composite } \\
\text { Reliability }\end{array}$ \\
\hline Knowledge Sharing & KNW & 5 & 0.887 & 0.901 \\
\hline Social Coordination & SCO & 4 & 0.892 & 0.902 \\
\hline Volunteerism & VOL & 5 & 0.932 & 0.932 \\
\hline Social cohesion & SOH & 5 & 0.907 & 0.920 \\
\hline $\begin{array}{l}\text { Humanitarian Crisis } \\
\text { (HUM }\end{array}$ & HUM & 8 & 0.855 & 0.865 \\
\hline
\end{tabular}

Table 2: Cornbach's alpha and composite reliability for the constructs. 
Citation: Salmen A, Ahmed M (2018) Knowledge Sharing in Social Media as Moderating Variable between Social Capital Online and Response to Humanitarian Crises. J Mass Communicat Journalism 8: 365. doi: 10.4172/2165-7912.1000365

measurement model. The second purpose of performing CFA was to test reliability, validity and unidimensionality of multi-item measures.

CFA analysis method was used to examine convergent validity for each variable. In addition, CFA contains several functions; these functions include testing the loading factors in every construct, estimating the measurement error in framework and confirming the instrument themselves which related to the latent variables. Therefore, CFA is deployed to determine the set of factors and construct loading items which confirm the requirement that is needed to measure.

\section{Measurement model}

CFA analysis method was employed to test convergent and discriminant validity for each variable. Moreover, the following sections explain CFA for exogenous and endogenous variables together. Final model showed the ratio of the chi-square to the degree of freedom was 2.498, less than 5 and RMSR was 0.088 less than 0.10 indicates a good model fit as well as the RMSEA was 0.064, less than 0.08 which is considered a good fit [40]. Also other measures indicated the GOF of the model to the data $(\mathrm{CFI}=0.932, \mathrm{IFI}=0.932$, TLI $=0.923)$ which indicate that the model employed in this study is a good fit to data [41,42]. Table 3 presents the resulting statistical estimate of measurement model for exogenous and endogenous variables. Figure 2 shows measurement model for exogenous and endogenous variables.

\section{Convergent and discriminant validity}

In this study, the factor loading for the items are more than 0.50 and IS acceptable if the study sample is more than 300 respondents [43] as shown in Figure 1. This, in turn, is sufficient evidence of convergent validity. Therefore, all indicators in the present study are related to their particular constructs, and thus there is satisfactory proof of the convergent validity of the model.

Discriminant validity gives the extent to which a construct is truly distinct from other constructs [44]. Discriminant validity is evaluated by using Average Variance Extracted (AVE) for every construct that exceeds the squared correlation among other constructs [45].

Discriminant validity was indicated, as the AVE values are more than the squared correlations for each set of construct. In addition, the square root of the AVE for a given construct was greater than the absolute value of the correlation square of the given construct with any another factor (AVE>correlation square). Table 3 shows the square

\begin{tabular}{|l|l|l|l|l|l|l|l|}
\hline & CR & AVE & HUM. & VOL. & SOH. & KNW. & SCO. \\
\hline HUM. & 0.861 & 0.502 & 0.710 & & & & \\
\hline VOL. & 0.937 & 0.748 & 0.658 & 0.865 & & & \\
\hline SOH. & 0.914 & 0.680 & 0.520 & 0.663 & 0.824 & & \\
\hline KNW. & 0.898 & 0.644 & 0.726 & 0.660 & 0.554 & 0.803 & \\
\hline SCO. & 0.894 & 0.679 & 0.367 & 0.280 & 0.244 & 0.293 & 0.824 \\
\hline
\end{tabular}

Table 3: Discriminant Validity (AVE) and C.R. for latent variables. root of the AVE for all constructs greater than the correlations between the construct and other constructs in the model.

\section{Structural model}

This study was conducted to test five direct hypotheses as discussed earlier. The hypothesized model includes: introduced, successful, identified BSC perspectives, learning and innovation, implementation obstacles on one endogenous variable which is organization's performance The aim for the hypothesized model is to test the relationship among constructs which is assessed by GOF such as (NFI ratio, IFI, TLI, CFI, NFI RMSEA, GFI, AGFI) which were carried out to test if the constructs fit the data.

The results of the structural model show the model fit indices such as the values of chi-square $\left(\chi^{2}\right)$ was 1283.895 and degrees of freedom was 548 . Furthermore, the findings show that normed $\chi^{2}$ value (ratio value) was 2.568 less than 5 , indicating sufficient fit. In addition, $\mathrm{CFI}=0.928, \mathrm{TLI}=0.919, \mathrm{IFI}=0.928$ and $\mathrm{RMR}=0.095$ is less than 0.10 which explains that the model employed in this research was a good fit to data. Moreover, the results also indicate that RMSEA $=0.067$ which was the recommended less than of 0.08 [40,43]. Figure 3 below shows the results of the structural model with Standardized Estimated (Goodness of Fit Indices).

\section{Direct Hypothesis Results}

The findings from the empirical study, as shown in this section, offered interesting results for discussion, which extended the earlier research in the areas of employees' turnover. As noted in Table 4, three direct hypotheses related to the aims of this study were developed and tested. These hypotheses are related to the direct path between the variables of this study and all of them were supported.

The empirical study tested six direct hypotheses related to the aim of the study. According to the results in Table 4, volunteerism is the important factor influence on knowledge management online and response to humanitarian crisis, among non-profit organizations in Yemen. The result indicates volunteerism had a significant and positive impact on knowledge management online and response to humanitarian crisis, $(\beta=0.510 ; C . R=6.609 ; P=0.000$ and $\beta=0.289$; $\mathrm{C} . \mathrm{R}=4.094 ; \mathrm{P}=0.000)$, respectively. Thus, $\mathrm{H} 2$ and $\mathrm{H} 5$ were supported. They are followed by social coordination and Social cohesion which had a significant and positive impact on response to humanitarian crisis and knowledge sharing ( $\beta=0$.202; $C . R=3.232 ; P=0.001$ and $\beta=0$ .146; $\mathrm{C} . \mathrm{R}=3.124 ; \mathrm{P}=0.002$ ). Therefore, $\mathrm{H} 4$ and $\mathrm{H} 3$ were supported among non-profit organizations in Yemen. However, social cohesion had insignificant effect on response to humanitarian crisis, thus $\mathrm{H} 6$ was not supported $(\beta=0.300 ; C . R=2.963 ; P=0.003)$.

\section{Indirect Hypothesis Results}

The findings show that the social coordination directly impacts

\begin{tabular}{|l|l|l|l|l|l|l|l|l|l|}
\hline Hypothesis & Exog. & $\Rightarrow$ & Endo. & Estimated & C.R & P-Value & Status & Result & Sig. \\
\hline H1 & Social Coordination & $\Rightarrow$ & Knowledge Sharing & 0.113 & 2.418 & 0.016 & Supported & Sig. \\
\hline H2 & Volunteerism & $\Rightarrow$ & Knowledge Sharing & 0.510 & 6.609 & 0.000 & 0.002 \\
\hline H3 & Social cohesion & $\Rightarrow$ & Knowledge Sharing & 0.146 & 3.124 & Sig. & Supported & Supported \\
\hline H4 & Social Coordination & $\Rightarrow$ & Humanitarian Crisis & 0.202 & 3.232 & 0.001 & 0.000 & Sig \\
\hline H5 & Volunteerism & $\Rightarrow$ & Humanitarian Crisis & 0.289 & 4.094 & 0.635 & 0.525 & Insig. \\
\hline H6 & Social cohesion & $\Rightarrow$ & Humanitarian Crisis & 0.037 & Not supported \\
\hline
\end{tabular}

Table 4: Direct hypotheses testing result of structural model. 
Citation: Salmen A, Ahmed M (2018) Knowledge Sharing in Social Media as Moderating Variable between Social Capital Online and Response to Humanitarian Crises. J Mass Communicat Journalism 8: 365. doi: 10.4172/2165-7912.1000365

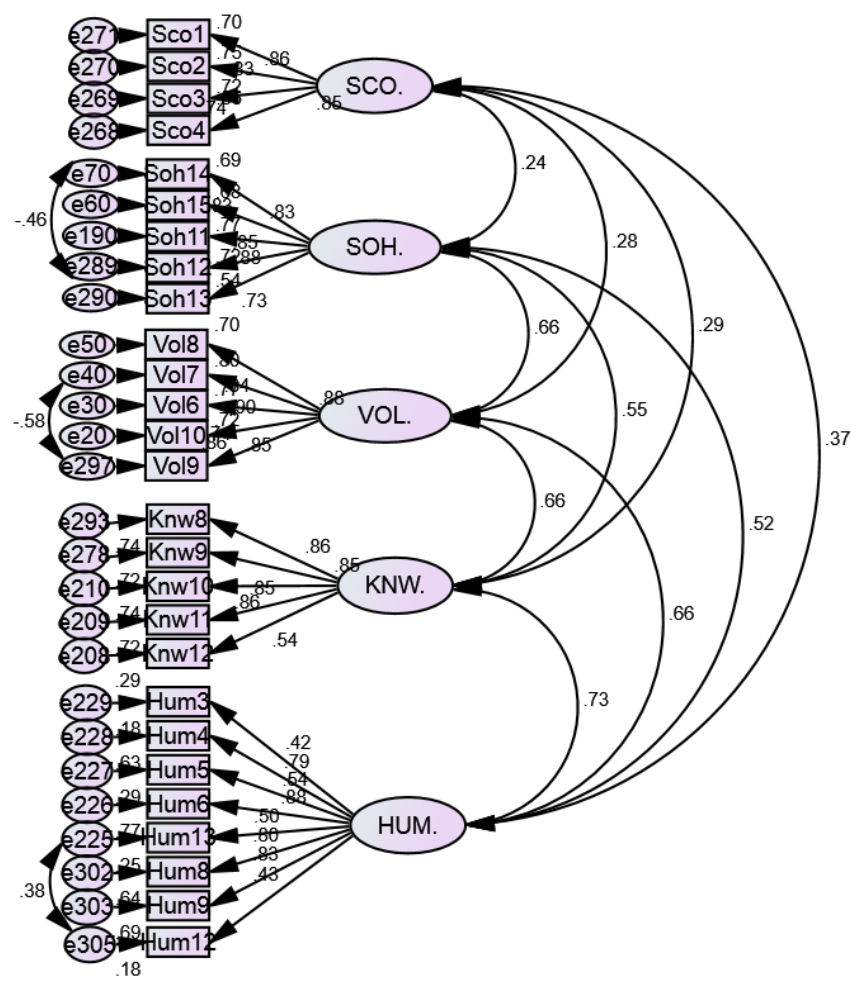

Figure 2: CFA for full measurement model.

\begin{tabular}{|l|l|l|l|l|}
\hline Hypothesis & Model & Direct effect & Indirect effect & Significant of indirect effect \\
\hline H7 & $\begin{array}{l}\text { Social coordination ---> response to humanitarian } \\
\text { crisis via knowledge sharing }\end{array}$ & 0.146 & 0.055 & $\begin{array}{l}\text { P=0.015 } \\
\text { Significant }\end{array}$ \\
\hline H8 & $\begin{array}{l}\text { Volunteerism -----> response to humanitarian crisis } \\
\text { via knowledge sharing }\end{array}$ & 0.289 & 0.249 & $\begin{array}{l}\text { P=0.000 } \\
\text { Significant }\end{array}$ \\
\hline H9 & $\begin{array}{l}\text { Social cohesion ---> response to humanitarian crisis } \\
\text { Via knowledge sharing }\end{array}$ & 0.037 & 0.098 & $\begin{array}{l}\mathrm{P}=0.016 \\
\text { Significant }\end{array}$ \\
\hline
\end{tabular}

Table 5: Structural parameters of the mediation role of knowledge sharing for the Relationship between Social Coordination, Volunteerism, Social cohesion and response to humanitarian crisis.

on response to humanitarian crisis and standardised coefficient was 0.146. And also social coordination indirectly impacts on response to humanitarian crisis through their impact on knowledge sharing with coreffeicint 0.055 and p-value is signficantly at 0.015 . Therefore, the result of the study indictes that knowledge management online is partial mediation between socila coordination and response to humanitarian crisis as shown in Table 5. In addition, volunteerism directly impacts on response to humanitarian crisis and standardised coefficient was 0.289. Moreover, volunteerism indirectly impacts on response to humanitarian crisis through their impact on knowledge management online with coreffeicint 0.249 and p-value is signficantly at 0.000 . Thus, the study's finding indictes that knowledge sharing is partial mediation between volunteerism and response to humanitarian crisis. Finaly, social cohesion directly impacts on response to humanitarian crisis and the standardised coefficient was 0.037 . However, social cohesion indirectly impacts on response to humanitarian crisis through their impact on knowledge management online with coreffeicint 0.098 and p-value is signficantly at 0.016 . So, the result of the study indictes that knowledge management online is full mediation between social cohesion and response to humanitarian crisis.

\section{Discussion and Conclusion}

The study empirically examined the role of social coordination, volunteerism and social cohesion online for responding to humanitarian crises and determining the mediation role of knowledge management between using of social media factors and responding to humanitarian crisis by non-profit organizations in Yemen. The findings of the study revealed that social coordination, volunteerism and social cohesion have a significant and positive influence on 
Citation: Salmen A, Ahmed M (2018) Knowledge Sharing in Social Media as Moderating Variable between Social Capital Online and Response to Humanitarian Crises. J Mass Communicat Journalism 8: 365. doi: 10.4172/2165-7912.1000365

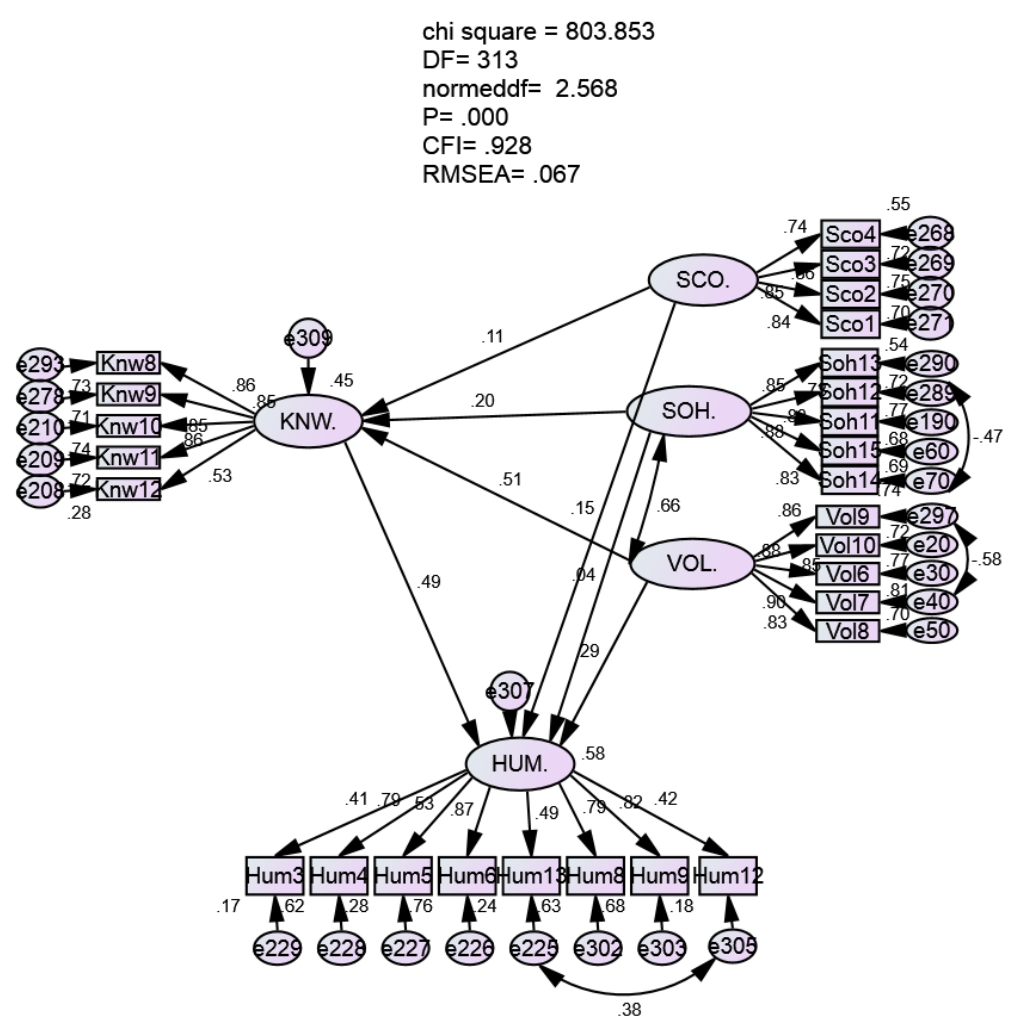

Figure 3: Goodness of fit indices.

knowledge sharing in social media and response to humanitarian crisis, but social cohesion has no significant on responding to humanitarian crisis among the non-profit organizations in Yemen. In addition, the results of the study show the social capital online factors which were considered as important factors that influence on response to humanitarian crisis and knowledge in social media among non-profit organizations especially in the Middle East and Yemen particularly. The results showed that knowledge management in social media was partial mediation between social coordination, volunteerism and response to humanitarian crisis, but it was full mediation between social cohesion and response to humanitarian crisis. It is through practice, preparation, and familiarity that social capital online factors can be used to the fullest in humanitarian responses. Furthermore, social capital online can be an extremely effective tool in these situations, and by optimizing its use, responders can better uphold the humanitarian imperative and alleviate suffering for more victims of humanitarian crises among non-profit organizations in Yemen. This study can serve as a guide to practitioners, social policy makers, governmental and nongovernmental as well as non-profit organizations. Moreover, this study will be beneficial to scholars in conducting studies about social and communication science in any country, and in Yemen in particular. Finally, findings of this study will serve as a rigorous guide to studies on the role of social capital online factors and response to humanitarian crises in the future, either in single or multiple case studies.

\section{Acknowledgments}

We would like to thank all who participated in the interviews for feedback and assistance. This project was supported by Al-awn Foundation for Development and Benevolent Fund for Outstanding Students in Yemen.

\section{References}

1. Kaplan AM, Haenlein M (2011) The early bird catches the news: Nine things you should know about micro-blogging. Bus Horiz 54: 105-113.

2. Reuter C, Scholl S (2014) Technical Limitations for Designing Applications for Social Media. In Mensch and Computer Workshopband, pp: 131-139.

3. Valecha R, Oh O, Rao R (2013) An exploration of collaboration over time in collective crisis response during the Haiti 2010 earthquake.

4. Fuchs G, Andrienko N, Andrienko G, Bothe S, Stange H (2013) Tracing the German centennial flood in the stream of tweets: first lessons learned. In Proceedings of the second ACM SIGSPATIAL international workshop on crowdsourced and volunteered geographic information, pp: 31-38.

5. Maxwell EM (2012) Motivations to Tweet: A uses and gratification perception of Twitter use during a natural disaster. IGARSS, pp: 1-5.

6. Falkheimer J (2006) When Place Images Collides: Place Branding and News Journalism. Nordicom.

7. Starbird K, Palen L (2011) Voluntweeters: Self-organizing by digital volunteers in times of crisis. In Proceedings of the SIGCHI conference on human factors in computing systems. Adv. Compos. Mater, pp: 1071-1080.

8. Patterson O, Weil F, Patel K (2010) The role of community in disaster response: conceptual models. Popul Res Policy Rev 29: 127-141.

9. Amichai Hamburger $Y(2008)$ Potential and promise of online volunteering Comput Human Behav 24: 544-562.

10. Burke M, Marlow C, Lento T (2010) Social network activity and social wellbeing. In Proceedings of the SIGCHI conference on human factors in computing systems. ADV COMPOS MATER, pp: 1909-1912.

11. Burke M, Kraut R, Marlow C (2011) Social capital on facebook. Proceedings of the 2011 Annual Conference on Human Factors in Computing Systems. CHI'11, pp: 571-580.

12. Valkenburg PM, Peter J (2007) Preadolescents' and adolescents' online communication and their closeness to friends. Dev Psychol 43: 267. 
Citation: Salmen A, Ahmed M (2018) Knowledge Sharing in Social Media as Moderating Variable between Social Capital Online and Response to Humanitarian Crises. J Mass Communicat Journalism 8: 365. doi: 10.4172/2165-7912.1000365

13. Kaigo M (2012) Social media usage during disasters and social capital: Twitter and the Great East Japan earthquake. Keio Communication Review 34: 19-35.

14. Merchant RM, Elmer S, Lurie N (2011) Integrating social media into emergencypreparedness efforts. N Engl J Med 365: 289-291.

15. Mathbor GM (2007) Enhancement of community preparedness for natural disasters: The role of social work in building social capital for sustainable disaster relief and management. Int Soc Work 50: 357-369.

16. Van Beuningen J, Schmeets $H$ (2013) Developing a social capital index for the Netherlands. Soc Indic Res 113: 859-886.

17. Cravens J (2006) Involving international online volunteers: Factors for success, organizational benefits, and new views of community. IJOVA 24: 15-23.

18. Zook M, Graham M, Shelton T, Gorman S (2010) Volunteered geographic information and crowdsourcing disaster relief: a case study of the Haitian earthquake. World Med Health Policy 2: 7-33.

19. Chang K (2010) Community cohesion after a natural disaster: insights from a Carlisle flood. Disasters 34: 289-302.

20. Wachtendorf T (2004) Improvising 9/11: Organizational improvisation following the world trade center disaster. University of Delaware.

21. Crandall W, Parnell JA, Spillan JE (2010) Crisis Management in the New Strategy Landscape.

22. Ahmad M, Zani NM, Hashim KF (2015) Knowledge sharing behavior among flood victims in Malaysia. ARPN J Eng Appl Sci 10: 968-976.

23. Kaklauskas A, Amaratunga D, Haigh R (2009) Knowledge model for postdisaster management. Int J Strateg Prop M 13: 117-128.

24. Yates D, Paquette S (2011) Emergency knowledge management and socia media technologies: A case study of the 2010 Haitian earthquake. IJIM 31: 6-13.

25. Chatfield AT, Akbari R, Mirzayi N, Scholl HJ (2012) Interactive effects of networked publics and social media on transforming the public sphere: A survey of Iran's leaderless' social media revolution'. In System Science (HICSS), 2012 45th Hawaii International Conference. IEEE, pp: 2552-2562.

26. Chiu CM, Hsu MH, Wang ET (2006) Understanding knowledge sharing in virtual communities: An integration of social capital and social cognitive theories. Decis Support Syst 42: 1872-1888.

27. Zhang D, Zhou L, Nunamaker JF (2002) A knowledge management framework for the support of decision making in humanitarian assistance/disaster relief. Know Inf Syst 4: 370-385

28. Balcik B, Beamon BM, Krejci CC, Muramatsu KM, Ramirez M (2010)
Coordination in humanitarian relief chains: Practices, challenges and opportunities. Int J Prod Econ 126: 22-34.

29. Hiltz SR, Diaz P, Mark G (2011) Introduction: Social media and collaborative systems for crisis management. ACM Trans Comput Hum Interact 18: 18.

30. Caitlin Kelley (2015) Women's Refugee Commission - Top 10 Needs Facing Refugees and Those Displaced in Emergencies.

31. Nel P, Righarts $M(2008)$ Natural disasters and the risk of violent civil conflict. Int Stud Q 52: 159-185.

32. Zlatanova S, Van Oosterom P, Verbree E (2004) 3D technology for improving Disaster Management: Geo-DBMS and positioning. In Proceedings of the XXth ISPRS Congress.

33. Gao H, Barbier G, Goolsby R (2011) Harnessing the crowdsourcing power of social media for disaster relief. IEEE Intell Syst 26: 10-14.

34. Lettieri E, Borga F, Savoldelli A (2004) Knowledge management in non-profit organizations. J KNOWL MANAG 8: 16-30.

35. Baran SJ, Davis DK (2011) Mass communication theory: Foundations, ferment, and future. Cengage Learning.

36. Matei SA (2010) What can uses and gratifications theory tell us about socia media? Hum Commun Res 3: 214-221.

37. Blumler JG, Katz E (1974) The uses of mass communication: Current perspectives on gratification research. SAGE.

38. Sathye M (1999) Adoption of Internet banking by Australian consumers: an empirical investigation. Int Bank Mar 17: 324-334.

39. Pikkarainen T, Pikkarainen K, Karjaluoto H, Pahnila S (2004) Consume acceptance of online banking: an extension of the technology acceptance model. Int Res14: 224-235.

40. Hair JF, Black WC, Babin BJ, Anderson RE, Tatham RL (1998) Multivariate data analysis. Uppersaddle River.

41. Schumacker RE, Lomax RG (2004) A beginner's guide to structural equation modeling. Psychology Press.

42. Lee KS, Lee HS, Kim SY (1970) Factors influencing the adoption behavior of mobile banking: a South Korean perspective. JIBC 12: 1-9.

43. Hair JF, Black WC, Babin BJ, Anderson RE, Tatham RL (2006). Multivariate data analysis 6th edn. Uppersaddle River: Pearson Prentice Hall.

44. Hair JF, Anderson RE, Black WB, Tatham RL (2010) Multivariate Data Analysis. Prentice Hall.

45. Fornell C, Larcker DF (1981) Evaluating structural equation models with unobservable variables and measurement error. J Mark Res 18: 39-50. 